\title{
De quanta memória precisa uma democracia? Uma reflexão sobre as relações entre práticas memoriais e práticas democráticas no Brasil atual ${ }^{\star}$
}

Benito Bisso Schmidt*

Resumo: O artigo, construído na forma de ensaio, busca analisar a relação entre práticas de memória e práticas democráticas, tendo como eixo projetos memoriais realizados no Brasil atual em relação à ditadura civil-militar iniciada em 1964. Para tanto, examina lugares de memória e manifestações da sociedade civil que evocam esse passado autoritário, pensando-os como integrantes da Justiça de Transição. Postula também a necessidade de uma memória exemplar a respeito da ditadura como elemento fundamental à construção de uma democracia vigorosa e de uma cidadania plena.

Palavras-chave: Ditadura Brasileira. Memória. Democracia. Justiça de Transição.

\section{Introdução}

Qualifico este texto de ensaio, com suas características de experimento, de tentativa, de incompletude, de liberdade reflexiva e de subjetividade. Ele se baseia, é claro, em uma série de leituras

\footnotetext{
" Uma versão com resultados parciais deste trabalho foi apresentada em abril de 2014 na mesa-redonda The dictatorship and its legacies, integrante do Simpósio Internacional Brazil: from dictatorship to democracy, ocorrido na Brown University. Professor do Departamento e do PPG em História da UFRGS. Doutor em História pela UNICAMP. E-mail: bbissos@yahoo.com
}

Anos 90, Porto Alegre, v. 22, n. 42, p. 153-177, dez. 2015 
realizadas para a minha pesquisa ${ }^{1}$ e meus cursos sobre as ditaduras no Brasil e na Argentina, mas não tem o acabamento e o grau de demonstração exigidos de um artigo acadêmico comme il faut. Resolvi seguir este caminho para propor à discussão algumas ideias que venho desenvolvendo sobre as relações entre práticas memoriais e práticas democráticas em sociedades pós-ditatoriais, com foco especial no caso brasileiro. Por isso, o que trago aqui é um convite ao debate, à reflexão conjunta, à crítica.

Além disso, este texto quer provocar, e por isso seu título é uma interrogação pouco usual: "De quanta memória precisa uma democracia?" Obviamente se trata de uma pergunta retórica, pois sabemos que não podemos medir a memória a partir de parâmetros quantitativos. A memória (e o esquecimento), apesar de seu fundo social e coletivo, é sempre um fenômeno subjetivo, cujos movimentos não se prestam à metrificação matemática. Então, normalmente nossas questões sobre o papel da memória nos processos de (re) democratização têm uma perspectiva qualitativa, por exemplo: de que memória precisamos para construir sociedades mais democráticas? Mas, ao mesmo tempo, falamos de "abusos" da memória (TODOROV, 2000) como a indicar que, em algum momento, as práticas memoriais sobre determinado passado podem "passar do ponto" e, por isso, ter efeitos deletérios. Ou seja, mesmo que inconscientemente, utilizamos uma certa mensuração (não matemática, é claro) para separarmos os usos e os abusos da memória, para caracterizarmos, utilizando a terminologia de Paul Ricoeur (2000), uma memória como "justa” em oposição a outras “injustas".

Tendo por base estas questões preliminares, quero, neste "ensaio provocador”, analisar as práticas memoriais em relação à ditadura civil-militar, instalada em 1964, no Brasil atual, buscando avaliar se a sua quantidade, mas especialmente a sua qualidade, são adequadas à construção de uma sociedade democrática. Chamo a atenção, mais uma vez, para a provisoriedade de minhas reflexões, já que, ao longo do ano de 2014, em função do cinquentenário do golpe, muitos novos acontecimentos afetaram a quantidade/qualidade destas memórias, especialmente a divulgação do relatório final da Comissão Nacional da Verdade, instalada em 2012 pela presidenta Dilma Rousseff para averiguar as graves violações aos direitos 
humanos cometidas entre 1946 e 1985, cujos resultados precisam ainda ser melhor avaliados. Portanto, o que aqui afirmo, se alguma consistência tem, pode perder a validade com o passar do tempo, mas esse é o risco que correm aqueles que se dedicam a pesquisar o chamado "tempo presente".

\section{Dos 40 aos 50 anos do golpe: permanências e transformações}

Aniversários redondos são bons para pensar sobre determinados fatos históricos, sobretudo para refletir sobre o que e por que as sociedades pensaram e pensam a respeito de tais fatos. Nestes momentos, práticas memoriais e práticas intelectuais acadêmicas (e não estou descartando as imbricações entre ambas) vêm à tona para recolocar certos temas na cena pública, algumas vezes somente a fim de afugentar o fantasma do esquecimento, em outras, para acrescentar novas leituras do passado em questão, reacendendo ou gerando tensões e debates entre diferentes visões.

Em 2004, quando transcorreram os 40 anos do golpe, foi assim: realizaram-se diversos seminários; inúmeras publicações, acadêmicas, jornalísticas e memoriais foram lançadas; a mídia se interessou pelo tema e batalhas memoriais travadas desde o final da ditadura ganharam novo fôlego, em especial aquelas que opõem o discurso oficial militar (que, muitas vezes, infelizmente, é acompanhado pelo discurso governamental), o qual tende a caracterizar como "revanchista" qualquer rediscussão pública da memória conciliadora do passado ditatorial imposta pela anistia de 1979 e oficializada pelos sucessivos governos democráticos (sem desconsiderar as diferenças entre eles); e o discurso das vítimas, de seus familiares e das organizações de direitos humanos, que, em diversos momentos, acentua a frustração desses agentes com as políticas oficiais referentes ao assunto.

Naquele momento, dois aspectos ganharam destaque nas discussões e rememorações referentes à ditadura: a frustração com o não aprofundamento das políticas reparatórias por parte do 
governo Lula, empossado no ano anterior, e a ênfase no papel dos arquivos para o esclarecimento da verdade em relação aos crimes cometidos pelos agentes repressivos. No que tange ao último aspecto, muito se falou da necessidade de abertura dos arquivos da ditadura, sendo que, seguidamente, os documentos neles contidos, quando localizados, eram percebidos publicamente como "[...] o reflexo, a verdade do que se passou, o testemunho mais exato da repressão, o segredo revelado, descoberto" (CATELA, 2002, p. 62, tradução nossa), desconsiderando-se as múltiplas relações de poder e saber implicadas na produção desses materiais e as inúmeras mediações que devem ser levadas em conta na sua interpretação. Enfim, a equação arquivos $=$ verdade $=$ justiça ganhou força nos debates públicos então ocorridos. Naquele contexto, a expressão "Justiça de Transição”, embora circulasse em determinados espaços políticos, jurídicos, sociais e intelectuais, não se projetou como uma fórmula icônica dos discursos memoriais, embora outras palavras a ela relacionadas - como justiça, verdade, reparação e memória circulassem amplamente.

Sublinho igualmente que, especificamente no âmbito acadêmico, passou-se a discutir mais sobre o apoio e/ou a indiferença de amplos setores da sociedade civil em relação à ditadura, criticando-se a representação que baliza a memória conciliadora deste passado, forjada nos anos finais do período autoritário, segundo a qual a ditadura militar "caiu" sobre o povo brasileiro, oprimindo-o durante vinte anos, até que fosse por ele derrubada. Muitas pesquisas voltaram-se à análise do apoio ativo ou passivo, ou mesmo da indiferença de importantes grupos componentes desse indefinido "povo brasileiro", como a imprensa, as universidades, os meios jurídicos, as camadas médias, entre outros. A expressão "ditadura civil-militar” passou a ter uma circulação mais ampla, mas, naquele momento, ainda sem força suficiente para substituir a poderosa imagem da "ditadura militar".

Dez anos depois, muitas das batalhas de memória permaneceram e se intensificaram, como a tradicional oposição, que mencionei anteriormente, entre o discurso militar (com ecos no mundo 
político e na sociedade civil) e o discurso das vítimas, familiares e grupos de direitos humanos (também com ressonâncias políticas e sociais): a acusação, por parte do primeiro, de revanchismo e da necessidade de levar em conta "os dois lados"; e a demanda, por parte do último, pelo aprofundamento da busca pela verdade e pela justiça; esses discursos continuam aparecendo amplamente na mídia, nas redes sociais, nos espaços políticos e nos ambientes acadêmicos. Porém, um novo elemento ganhou destaque nos embates memoriais: a noção de Justiça de Transição, e isso obviamente está relacionado à atuação da Comissão da Verdade. Interessante que, muitas vezes, estes dois elementos - Justiça de Transição e Comissão da Verdade - são vistos quase como sinônimos, quando, na verdade, o segundo é apenas um elemento do primeiro, o qual envolve um conjunto bem mais amplo de práticas, sendo que algumas delas já estão em uso no Brasil há vários anos, como as políticas de reparação financeira, regulamentadas, pelo menos, desde 2002. De qualquer maneira, parece-me, é com a Comissão da Verdade que se passa a falar mais na arena pública de Justiça de Transição, embora, repito, esse termo não estivesse ausente em momentos anteriores. Já a questão da abertura dos arquivos, no sentido de "segredo a ser revelado", parece ter menos ressonância nos discursos memoriais hoje, certamente em função do avanço no processo de publicização de vários destes acervos (como o do Serviço Nacional de Informação - SNI, por exemplo), para o qual cabe destacar o importante papel do Centro de Referência das Lutas Políticas no Brasil - Memórias Reveladas, que busca articular uma rede de arquivos e centros de documentação detentores da guarda de materiais relevantes para o conhecimento da história política brasileira entre 1964 e 1985. Também a expressão "ditadura civil-militar" passou a circular com muito mais intensidade para além dos espaços acadêmicos, mesmo que nem sempre implicando uma efetiva reflexão sobre o apoio da sociedade ao golpe e aos governos autoritários, e que a ideia seja criticada por alguns estudiosos (MARTINS FILHO, 2014; MELO, 2012). 


\section{Justiça de Transição e práticas memoriais}

Na obra Justiça de Transição - Manual para a América Latina, publicada em 2011 pela Comissão da Anistia do Ministério da Justiça, aliás, um dos agentes mais dinâmicos da Justiça de Transição

$\infty$ no Brasil (e das políticas memoriais referentes à ditadura) desde que 1 foi criado em 2002, consta a tradução de um artigo (publicado originalmente em 2005) de Paul van Zyl, jurista e ativista dos direitos humanos, diretor executivo do PeaceVentures, secretário executivo da Comissão de Verdade e Reconciliação da África do Sul entre 1995 e 1998 e cofundador e ex-vice-presidente do Centro Internacional para a Justiça de Transição (ICTJ), portanto uma autoridade reconhecida no assunto. $\mathrm{O}$ autor define justiça transicional como "[...] o esforço para a construção da paz sustentável após um período de conflito, violência em massa ou violação sistemática dos direitos humanos" (ZYL, 2011, p. 47) e aponta cinco elementos-chave que a comporiam: a própria justiça, no sentido estrito de julgamento dos perpetradores; a busca da verdade; as políticas de reparação; as reformas institucionais; e a reconciliação. A dosagem desses elementos e sua efetivação dependeriam de cada contexto nacional e do tipo de conflito que se deseja superar (governo ditatorial ou guerra civil, principalmente). Não vou me ater a todos esses pontos, mas pode-se dizer que o Brasil avançou em termos de políticas de reparação, sobretudo no que se refere ao aspecto financeiro, e tenta progredir, no que tange à busca da verdade, com a atuação da Comissão Nacional da Verdade e suas correlatas nos estados, órgãos públicos, sindicatos, entre outros espaços. Quanto à Justiça, o Supremo Tribunal Federal reafirmou em 2010 a interpretação vigente da Lei da Anistia de 1979, que impediu o julgamento dos "crimes conexos" àqueles praticados pelos anistiados, segundo o texto legal, incluindo-se nestes aqueles perpetrados pelos agentes da repressão estatal. Contudo, há indícios de que o trabalho de alguns componentes da Comissão da Verdade, a pressão dos movimentos de direitos humanos e de certos operadores do Direito (como o Ministério Público e a Ordem dos Advogados do Brasil) e, sobretudo, uma nova composição mais progressista da instância 
máxima do poder judiciário no Brasil possam reverter esse fato e permitir o julgamento dos que violaram os direitos humanos no período ditatorial.

No que diz respeito às reformas institucionais, no sentido proposto por van Zyl de modificação profunda ou mesmo supressão de instituições responsável pelas violações de direitos humanos e de depuração e saneamento administrativo, parece-me que avançamos pouco. Se bem passamos a ter um Ministério da Defesa encabeçado por um civil no lugar dos outrora poderosos ministérios correspondentes a cada braço das Forças Armadas, sempre liderados por membros de tais forças, ainda verifica-se o poder dessa corporação quando o assunto é esclarecer as violências cometidas no período ditatorial, inclusive impedindo o acesso a arquivos. Outro exemplo que indica a permanência de uma memória forjada no período ditatorial no seio das Forças Armadas é o fato de que os livros didáticos utilizados nas escolas militares, ao contrário daqueles adotados nas escolas civis públicas, não são submetidos à avaliação das equipes do Ministério da Educação, as quais buscam examinar, no caso dos livros de História (que são os que conheço melhor), se esses estão em sintonia com a produção historiográfica mais recente; se não contêm discriminações raciais, de gênero, de classe, de região, de geração, entre outras; e se colaboram para a construção de uma cultura da paz, de respeito à diversidade e aos direitos humanos. Como não passam por este crivo e seguidamente são escritos por historiadores ligados à corporação, os manuais de História empregados nas escolas militares continuam reproduzindo noções como a de que o golpe de 64 foi uma "revolução democrática" que salvou o Brasil do comunismo e permitiu ao país avançar no caminho do progresso e da modernidade.

Sobretudo: se já não temos mais os temíveis DEOPS, não é segredo para ninguém que a polícia continua empregando tortura para obter informações, assassinando muitos que ousam questionar seus métodos e sumindo com os corpos, ou alegando suicídios e tentativas de resistência daqueles que sucumbem aos excessos de suas "práticas investigativas" (práticas, aliás, que precedem temporalmente o próprio golpe de 64). Nesse sentido, a demanda pela desmilitarização das polícias, muito ouvida nas manifestações

Anos 90, Porto Alegre, v. 22, n. 42, p. 153-177, dez. 2015 
populares de junho de 2013, enfrenta fortes resistências. Aliás, a truculência da atuação policial contra os manifestantes nos últimos tempos desmente qualquer ideia de uma mudança significativa destes órgãos de segurança, no sentido de haver maior respeito aos direitos humanos.

Finalmente, em relação à "reconciliação", ideia controversa e polissêmica, mas que significa basicamente superar as rivalidades e inimizades que geraram os acontecimentos traumáticos, penso que, contraditoriamente, ao menos no caso do Brasil, primeiro temos que nos desfazer da ideia mesma de reconciliação para depois atingi-la. Ou seja, precisamos, por diversos mecanismos - jurídicos, políticos, pedagógicos, culturais, etc. -, livrar-nos da nossa identidade de eternos conciliadores e fazermos aflorar (no âmbito do Estado de Direito) a conflitividade que marcou e marca a nossa história, para, daí sim, pensarmos em reconciliação. Afinal, como ressalta van Zyl, "[...] se a reconciliação deve ser aceita, não pode reduzir-se a ignorar o passado, negando o sofrimento das vítimas ou subordinando a exigência da prestação de contas e a reparação a uma noção artificial de unidade nacional” (ZYL, 2011, p. 55).

No texto de Zyl, a questão das políticas de memória aparece especialmente no item referente às reparações, mais especificamente quando o autor se refere às medidas simbólicas e cita, como exemplo, monumentos, memoriais e dias de comemoração nacionais. É neste tipo de prática que quero me deter com mais atenção a partir de agora.

Ao contrário da Argentina, por exemplo, onde proliferam espaços de memória em várias cidades do país, onde os antigos centros de detenção e tortura (como a tristemente célebre Escola de Mecânica da Armada - ESMA) foram transformados em lugares de lembrança e de homenagem às vítimas, onde placas e monumentos inscrevem no espaço urbano as marcas do passado ditatorial, incitando a lembrança e, em alguns casos, a reflexão, no Brasil são poucos os casos de iniciativas, tanto do Estado quanto da sociedade civil, de edificação ou de demarcação de lugares semelhantes. Não quero tomar o caso argentino como modelo ideal, pois bem sei dos interesses políticos e pessoais que motivam muitos desses 
projetos e também das exclusões nele presentes (como de representar as violências perpetradas pelo último governo de Perón), mas apenas indicar que, diferentemente do país vizinho, o Brasil não tem sido pródigo em implementar espaços memoriais consagrados à recordação da ditadura. Deve-se, porém, ressalvar que, como disse acima, no Brasil os arquivos da ditadura estiveram no centro das batalhas de memória em 2004 e muitos avanços foram feitos no sentido de torná-los públicos (bem mais do que na Argentina, para prosseguirmos na comparação); talvez, tenham sido essas instituições e acervos que se tornaram os lugares de memória por excelência para a recordação da repressão ditatorial.

Mas voltemos aos exemplos propostos por van Zyl: no Brasil, não temos nenhuma data nacional, sancionada oficialmente, voltada à lembrança das vítimas das violências da ditadura. $\mathrm{O}$ próprio 31 de março/ $1^{\circ}$ de abril tem servido a este propósito, mas normalmente de maneira informal. Quanto aos memoriais, cito o exemplo mais conhecido, o Memorial da Resistência, localizado no centro da cidade de São Paulo, que ocupa o prédio onde funcionou o Departamento Estadual de Ordem Política e Social (DEOPS) do estado entre 1940 e 1983. Em 1999, o prédio foi tombado como bem cultural pelo órgão municipal de patrimônio e iniciou-se um projeto de restauração, concluído em 2002. Neste ano, foi criado o Memorial da Liberdade, abrangendo o espaço das antigas celas do Departamento. Em 2004, a Pinacoteca do estado assumiu a gestão do prédio, destinando-o ao desenvolvimento de atividades museológicas no campo das artes visuais. Em 2007, o Memorial da Liberdade recebeu um novo projeto museológico, voltado à "problematização e atualização de distintos caminhos das memórias da resistência e da repressão políticas do Brasil republicano”. No processo de ressignificação daquele espaço teve papel fundamental, desde fins de 2006, a militância de grupos de direitos humanos junto ao governo estadual, especialmente do Fórum Permanente de ex-Presos e Perseguidos Políticos do Estado de São Paulo. A implantação do novo projeto foi iniciada em $1^{\circ}$ de maio de 2008 , com a mudança do nome para Memorial da Resistência. ${ }^{2}$ 
O Memorial apresenta como sua missão institucional

[...] a pesquisa, a salvaguarda e a comunicação de referências das memórias da resistência e da repressão políticas do período republicano brasileiro [...] de forma a contribuir para a reflexão crítica acerca da história contemporânea do país e para a valorização de princípios democráticos, do exercício da cidadania e da conscientização sobre os direitos humanos.

Apesar da abrangência temporal reivindicada - o período republicano brasileiro - percebe-se que, tanto em suas exposições quanto em suas ações educativas e culturais, o Memorial da Resistência volta-se, sobretudo, para as memórias do período ditatorial instaurado em 1964. A parte mais impactante de sua museografia é aquela que busca reconstituir cenograficamente o aspecto das antigas celas do DEOPS, de forma a evidenciar aos visitantes as violências a que eram submetidos os presos políticos (museografia, aliás, que se assemelha a de outras instituições que buscam presentificar o trauma, as quais têm como parâmetro aquela implantada em Auschwitz). 


\section{Imagem 1: Memorial da Resistência (SP)}

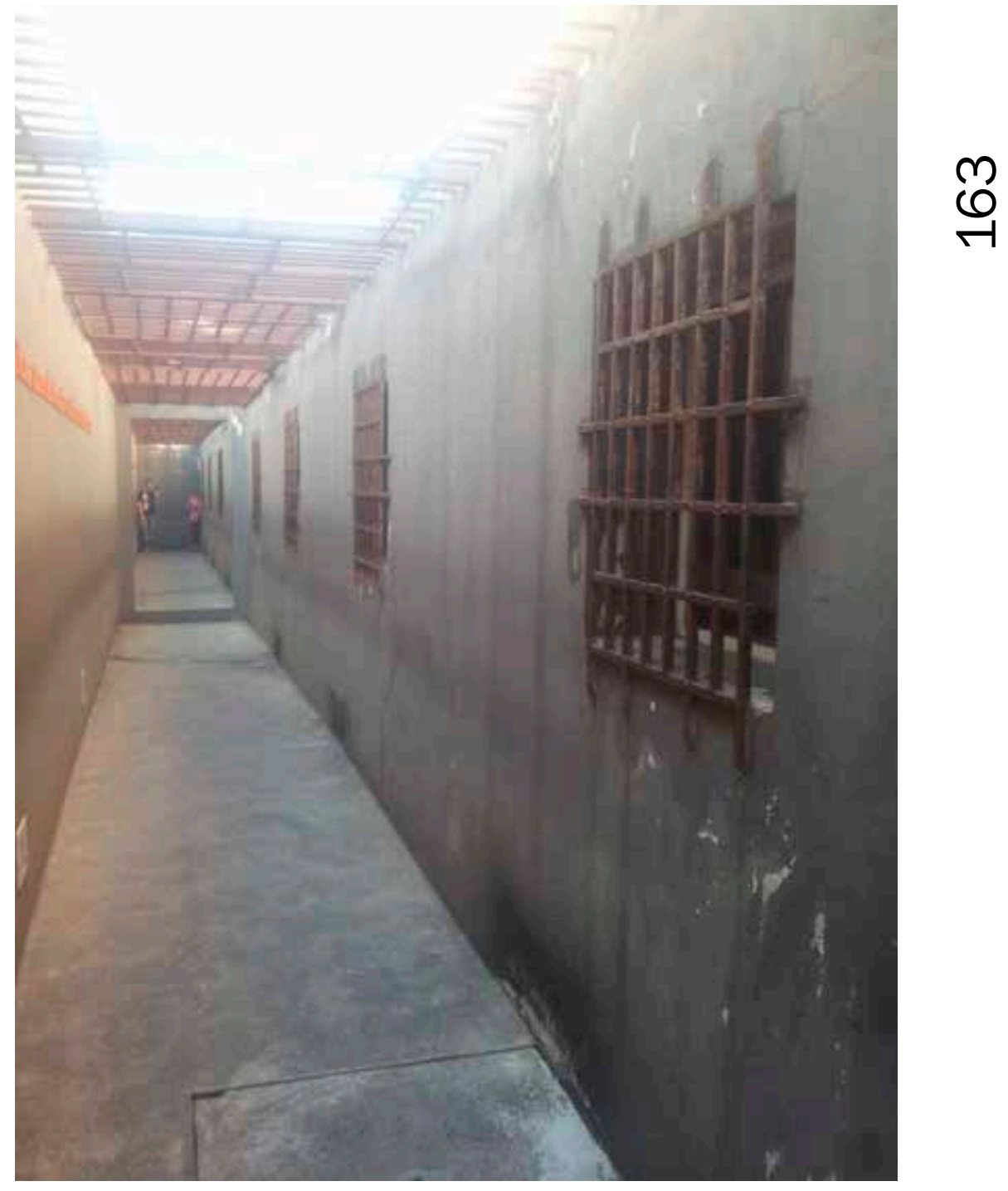

Foto: Elvis Carissimi

Anos 90, Porto Alegre, v. 22, n. 42, p. 153-177, dez. 2015 
Interessante também notar que o Memorial busca estender sua ação para além do espaço físico que ocupa através do programa "lugares de memória", o qual visa inventariar e sinalizar espaços da cidade que "[...] registram as memórias das ações de controle, repressão e resistência políticas durante os dois regimes autoritários - Estado Novo (1937-1945) e a Ditadura Militar (1964-1985), e em períodos de democracia [...]”. Dos 13 lugares já inventariados, ao menos 8 referem-se exclusivamente às memórias da ditadura civil-militar, ${ }^{3}$ e os demais dizem respeito a espaços que foram palco de diversas ações de repressão e resistência ao longo do período republicando, incluindo o período ditatorial recente. ${ }^{4}$

Quanto aos monumentos, estes também ainda são poucos. Destaco o Tortura Nunca Mais, localizado em Recife e inaugurado em 1993, iniciativa da prefeitura da cidade em resposta à pressão dos movimentos de familiares de mortos e desaparecidos políticos e de outros organismos de direitos humanos. O monumento, em sua concepção estética, consegue aglutinar várias temporalidades: a Revolução Francesa com a guilhotina, a ditadura brasileira com o "pau de arara" e a escravidão, já que a representação do corpo do torturado remete a imagens já incorporadas no imaginário coletivo das violências infligidas aos cativos. Além disso, está situado no cruzamento de duas ruas importantes para a história da cidade (Rua da Aurora e Rua Maria Melo), especificamente na Praça Padre Henriquez, a qual homenageia esse religioso, assessor do arcebispo Dom Hélder Câmara, brutalmente assassinado em 1969. Segundo Valdenia Brito,

[...] a estética do monumento [...] pode dar chaves para explorar o delicado jogo entre as torturas do passado cometidas pelo regime militar e a oposição mais total às violações aos direitos humanos no presente e no futuro, assim como o jogo entre a localização específica em Recife e a mensagem mais ampla dirigida a todo o Brasil, ou inclusive à humanidade (BRITO, 2003, p. 119, tradução nossa). 


\section{Imagem 2: Monumento Tortura Nunca Mais (Recife)}

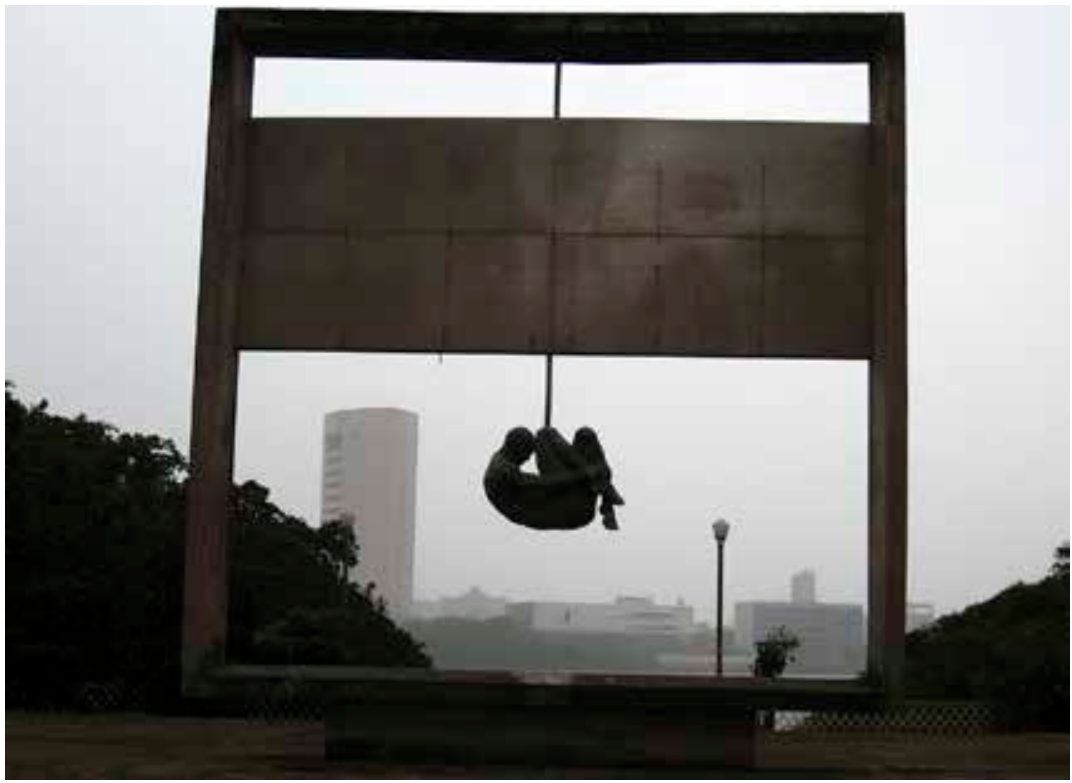

Fonte: <https://pt.wikipedia.org/wiki/Monumento_Tortura_Nunca_Mais\#/ media/File:Monumento_Tortura_Nunca_Mais_-_Recife.jpg>. Acesso em: 22 mar. 2014.

Gostaria também de referir o caso do principal museu histórico do país, o Museu Histórico Nacional, situado no Rio de Janeiro. Em 2006, a instituição inaugurou sua nova exposição de longa duração, cujo objetivo é, segundo o site do museu, abranger da pré-história brasileira ao período republicano, através do acervo tradicional, de peças contemporâneas e de recursos multimídia, de modo a auxiliar "[...] o visitante na compreensão de nossa história". A exposição, belíssima em termos estéticos, segue uma ordem cronológica pautada nos marcos consagrados da história política, embora com denominações mais modernas: a tradicional pré-história recebe o nome indígena Oreretama; o período colonial torna-se Os portugueses no mundo; o Império, A construção da Nação; e a República, Cidadania em construção. Porém, neste último módulo, a cronologia desaparece em função do tema geral dos direitos, 
objetivando, ainda segundo o site institucional, "[...] a reflexão sobre o processo de construção da cidadania, a partir dos direitos individuais, políticos e sociais ${ }^{5 ”}$. Contudo, em nenhum momento são referidas a ditadura civil-militar, as violações dos direitos humanos perpetradas pelos governos autoritários e as resistências e apoios ao regime. Aliás, em uma tela, são projetadas imagens dos presidentes da República, do Marechal Deodoro à presidenta Dilma, em uma continuidade sem diferenciações entre, por exemplo, presidentes eleitos democraticamente e aqueles impostos por meio da força. Portanto, na mais consagrada narrativa museológica da história nacional, em muitos pontos atualizada com a historiografia recente (como quando apresenta, através de imagens, a construção do mito de Tiradentes), a ditadura "some" e a história recente do Brasil se dilui em um difuso processo de conquista de direitos, abarcando um leque que vai dos direitos políticos e sociais ao "direito de brincar".

Voltando aos projetos memoriais relacionados à ditadura antes citados, percebe-se que todos eles apoiam-se na ideia do "nunca mais", ou seja, de que lembrar é fundamental para que as violências cometidas no passado não se repitam nem no presente nem no futuro. Tal perspectiva fica ainda mais clara em outro slogan dos movimentos de direitos humanos: "Para que não se esqueça, para que nunca mais aconteça", lema inclusive do projeto Memórias reveladas, que referi acima. É esta chave que legitima a justiça transicional e sua implementação em diversos países. Ela se ancora em um regime de historicidade conhecido como "história mestra da vida”, o qual postula que o passado é um repositório de exemplos e contraexemplos aos homens do presente, daquilo que deve ser imitado e daquilo que deve ser evitado (HARTOG, 1997; KOSELLECK, 2006). A ideia do "nunca mais" baseia-se em uma esperança nem sempre verificada empiricamente: a de que o conhecimento das atrocidades cometidas no passado vai nos auxiliar a construir um presente e um futuro mais pacíficos e democráticos. Conforme refere o historiador Antoine Prost:

A demanda de memória comporta sempre uma dimensão afetiva: o que se passou, cuja memória deve ser guardada, é seguidamente um teste, um drama, uma tragédia. As cicatrizes não estão totalmente fechadas e a ferida continua viva. 
Evocar então um dever de memória é convidar a sociedade inteira a compartilhar uma indignação, uma revolta ou um luto, e a transformá-los em resolução (PROST, 2000, p. 5, tradução nossa).

Mas como levar a "sociedade inteira" a compartilhar esta indignação e transformar tal sentimento em resolução, sobretudo na decisão de não repetir o passado? Especificamente em relação aos monumentos e tratando do caso uruguaio, Hugo Achugar apresenta questões interessantes: "Existe uma justiça do monumento? É possível uma justiça em nossas sociedades democráticas que dê conta da tensão entre esquecimento e memória? $\mathrm{O}$ monumento é a solução?” (ACHUGAR, 2003, p. 214, tradução nossa). E ainda: serão esses "monumentos consensuados", com sentido nacional, ou serão considerados como produtos de administrações e movimentos específicos? (Ibid., loc. cit.). Terão a capacidade de interpelar a "sociedade inteira" ou, ao menos, parcelas significativas da população, ou dialogarão apenas com os valores, representações e projetos daqueles grupos diretamente relacionados ao passado que se quer imortalizar? Voltando à nossa questão inicial: existe uma "boa medida" para as iniciativas memoriais de forma a garantir sua eficácia como motivadoras à construção de valores democráticos?

$\mathrm{Na}$ França, por exemplo, o Affaire Dieudonné, ator cômico que faz sketches antissemitas e que passou a atrair um número significativo de admiradores, sobretudo jovens, levou ao questionamento de que, talvez, essa atração pudesse resultar de um excesso de memórias sobre a Shoah, sobretudo no ensino escolar. Posicionando-se diante da discussão, o historiador Tal Bruttman sugeriu a seguinte explicação: "O objeto histórico [Shoah] é onipresente na sociedade, ele se encontra memorializado, midiatizado, politizado e, enfim, sacralizado. E o que há de mais subversivo, para um jovem, do que atacar aquilo que os adultos consideram como sagrado?" (BRUTTMAN apud BATTAGLIA, 2014, p. 10, tradução nossa). Estamos longe, é claro, de qualquer sacralização mais ampla da memória da ditadura no Brasil, mas não poderíamos pensar em projetos memoriais que tendam não à sacralização do passado (e, consequentemente, ao seu congelamento como "objeto de culto") e sim à interpelação constante do presente e do futuro? 
Uma chave que pode ajudar-nos a pensar esta questão é a distinção feita por Tzvetan Todorov, em livro significativamente intitulado Os abusos da memória, entre memória literal e memória exemplar: a primeira não conseguiria ultrapassar os limites do evento em si, a sua literalidade, permanecendo intransitiva e não levando mais além de si mesma; já a segunda, sem deixar de considerar a singularidade do evento recordado, se abriria à analogia e à generalização, transformando-se "em princípio de ação" e permitindo a utilização do passado para lutar contra as injustiças do presente (TODOROV, 2000, p. 30-31). Mas como pensar em projetos memoriais que tenham por horizonte a exemplaridade da memória e não a sua literalidade?

Alguns casos recentes, vindos não do governo, mas da sociedade civil, e protagonizados sobretudo por jovens, parecem-me interessantes para refletir a respeito do diálogo entre passado e presente, entre projetos memoriais e projetos que visam à ampliação da democracia.

Um deles é a iniciativa manifestada por alunos de várias escolas que têm nomes de ditadores, como Costa e Silva, Castelo Branco e até Médici, de mudarem essas designações. Seguidamente, tais demandas são motivadas por professores, mas chama a atenção como elas conseguem aglutinar um número significativo de estudantes. Este é o caso, por exemplo, da Escola Costa e Silva, de Porto Alegre. No Facebook do movimento pela mudança do nome, busca-se esclarecer aos alunos sobre quem foi Costa e Silva:

Tu sabe quem foi o ditador Costa e Silva? Como disse a pergunta, o cara foi um ditador que fez parte de um processo que manchou ainda mais a história do Brasil e não faz muito tempo não, certamente se vocês perguntarem pros avós, talvez os pais, sobre como era naquela época, com certeza virão umas histórias macabras por aí (TU SABE..., 2013).

A seguir, são mencionados alguns acontecimentos relacionados ao personagem, inclusive o fato de que ele assinou o AI-5, "[...] que fez com que a tortura aos presos se tornasse justificável e dava aos torturadores impunidade e que hoje muitos deles, esses assassinos 
torturadores tão vivos e alguns ainda nas delegacias e quartéis, ou estão aposentados ganhando uma grana F..." (TU SABE..., 2013). Prosseguindo na articulação entre passado e presente, e enfatizando o caráter exemplar da memória da ditadura, o texto afirma:

A partir do governo Costa e Silva o número de presos e desaparecidos só aumentou ano após ano. E hoje temos muito legado daquela época, e só ver o que são as cadeias, a repressão no morro contra o pobre, o trabalhador e a trabalhadora, contra o negro, enfim, a ditadura continua e a gente nem sabia que fazia tanto tempo que ela começou e pior ainda homenageamos os ditadores/assassinos colocando nomes em escolas. ${ }^{6}$

Diante das alegadas dificuldades burocráticas e legais para a mudança do nome, muitos alunos passaram a chamar a sua escola de "Costinha", em alusão ao famoso cômico brasileiro Lírio Mário da Costa, valendo-se da ironia para atacar a memória oficial consolidada na designação Costa e Silva.

\section{Imagem 3: Ditador Emílio Garrastazu Médici}

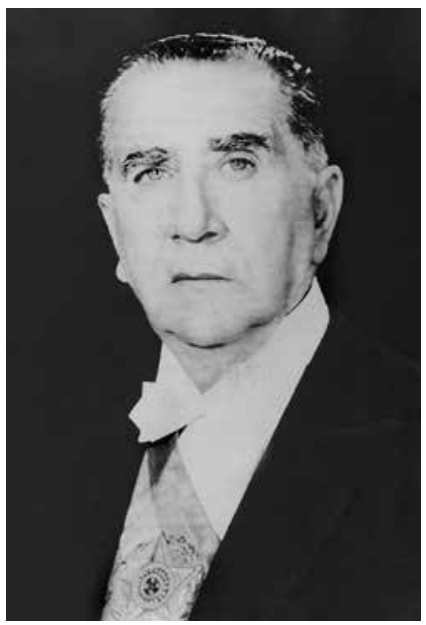

Fonte: $<$ https://pt.wikipedia.org/wiki/Em\%C3\%ADlio_Garrastazu_M\%C3\%A9dici\#/media/File:Garrastazu_m\%C3\%A9dici.jpg>. Acesso em: 22 mar. 2014.

Anos 90, Porto Alegre, v. 22, n. 42, p. 153-177, dez. 2015 


\section{Imagem 4: Comediante Lírio Mário da Costa, o "Costinha"}

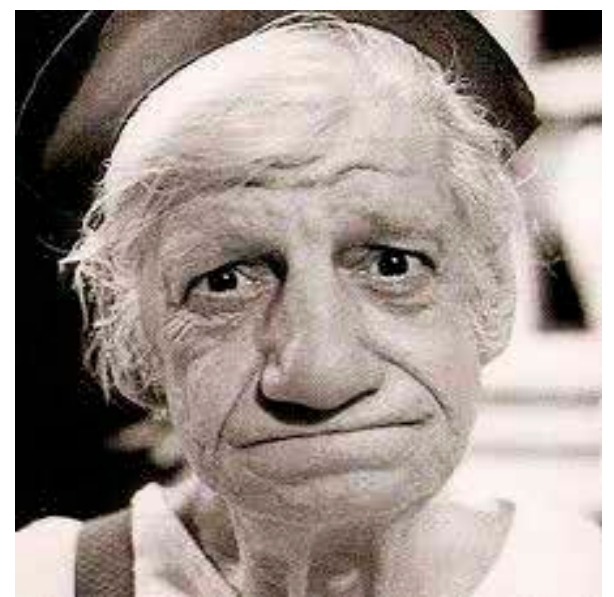

Fonte: <https://pt.wikipedia.org/wiki/Costinha_\%28humorista\%29\#/media/ File:Costinha.jpg>. Acesso em: 22 mar. 2014.

Em outra situação, a de um colégio da Bahia, por incentivo de uma professora de Sociologia, propôs-se trocar o nome do estabelecimento de Garrastazu Médici para Marighella, baiano, um dos mais importantes líderes da luta armada no Brasil. Os alunos, inclusive, realizaram uma exposição sobre o guerrilheiro. A troca de nome acabou sendo efetivada no mês de fevereiro de 2014. Aliás, o nome de Marighella voltou a aparecer em muitos muros durante as manifestações de junho de 2013. E é tratando destes movimentos que quero concluir o presente artigo.

Anos 90, Porto Alegre, v. 22, n. 42, p. 153-177, dez. 2015 


\section{Imagem 5: Pichação em muro de Porto Alegre.}

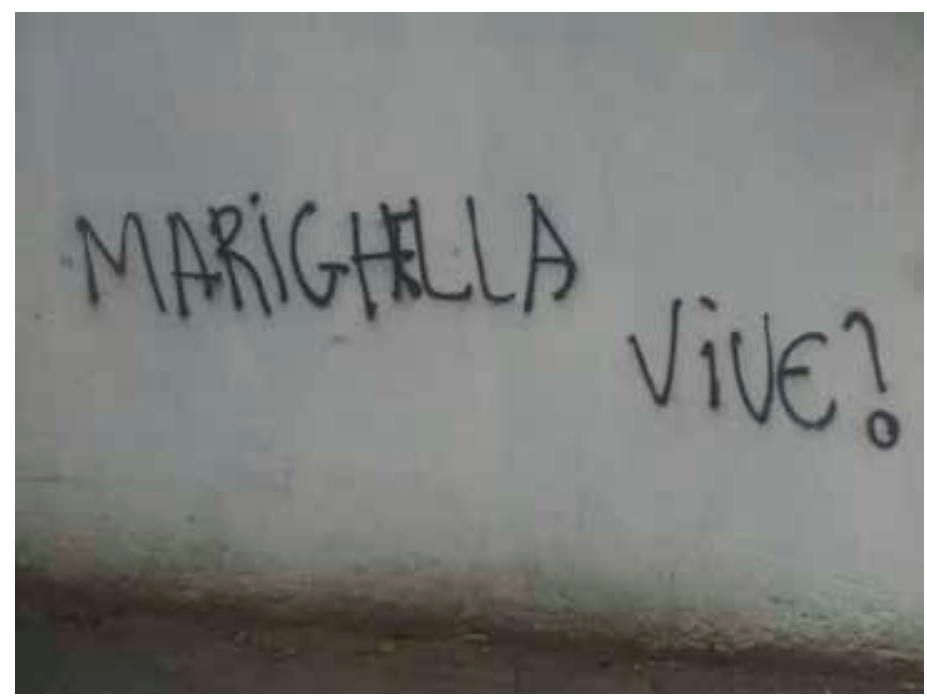

Foto: Elvis Carissimi

\section{Considerações finais: em busca da "boa memória”}

Tais mobilizações foram extremamente heterogêneas em seus propósitos, formas de ação e composição. Iniciaram por articulação do Movimento Passe Livre, que reivindica a gratuidade dos transportes públicos e, naquele momento, especificamente em São Paulo, demandava que os preços das passagens de ônibus não fossem aumentados. Porém, com o desenrolar dos movimentos (e insisto no uso do plural), muitos grupos foram às ruas: de anarquistas a conservadores anti-petistas. Interessa-me aqui, contudo, apontar que a memória da ditadura foi reativada durante as mobilizações, tanto por aqueles que se mostraram saudosos do regime autoritário quanto, e sobretudo, pelos que estabeleceram uma ponte entre o passado e o presente em suas reivindicações. Em relação aos últimos, chamaram-me a atenção duas palavras de ordem. 


\section{Imagem 6: Manifestação (RJ, 2013)}

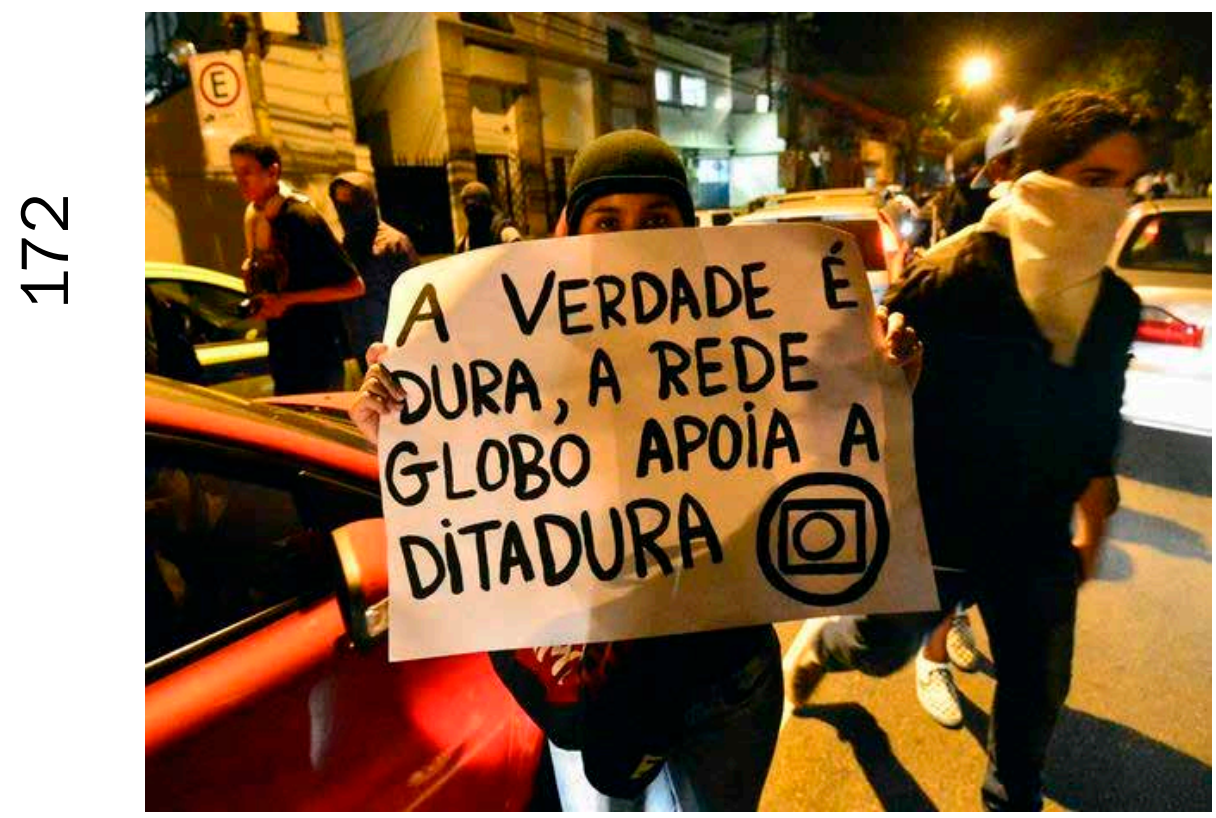

Fonte: <http://www.viomundo.com.br/wp-content/uploads/2015/04/globo_ditadura.jpg>. Acesso em: 22 mar. 2014.

A primeira - "A verdade é dura, a Globo apoiou a ditadura" refere-se ao apoio da principal empresa de comunicação brasileira, a Rede Globo, ao golpe e à ditadura. Pouco tempo depois, o que se designou como "a voz das ruas" acabou motivando uma retratação pública da empresa. O seu principal jornal, $O$ Globo, ressaltou, em editorial, que a decisão de fazer uma "avaliação interna" sobre o apoio ao regime ditatorial veio antes das manifestações populares. Mas "as ruas", afirma $O$ Globo, "[...] nos deram ainda mais certeza de que a avaliação que se fazia internamente era correta e que o reconhecimento do erro, necessário" (O GLOBO, 2013). O texto apresentou um pedido de desculpas e afirmou a democracia como valor absoluto. Em uma passagem, contudo, a direção da Rede Globo deu a entender que fora enganada pela promessa dos militares de uma intervenção "passageira, cirúrgica", e que, "ultrapassado o perigo de um golpe à esquerda", o poder voltaria aos civis por meio 
de eleições diretas (O GLOBO, 2013). Ressaltou também que seu principal dirigente, Roberto Marinho, sempre se posicionou contra a perseguição a jornalistas de esquerda. Apesar de sua ambiguidade, o editorial evidencia o poder da memória exemplar evocada pelos manifestantes, que não se contenta em reviver o passado, mas sim busca, através de recordações pretéritas, questionar o presente. Neste sentido, investe contra a antes referida memória conciliadora da ditadura, que representa esse regime como um mal que se abateu "sobre" a sociedade brasileira, ao evidenciar o apoio de importantes setores da sociedade civil (nesse caso, a imprensa) aos governos autoritários, apoio esse que foi silenciado quando da redemocratização.

\section{Imagem 7: Manifestação (RJ, 2013)}

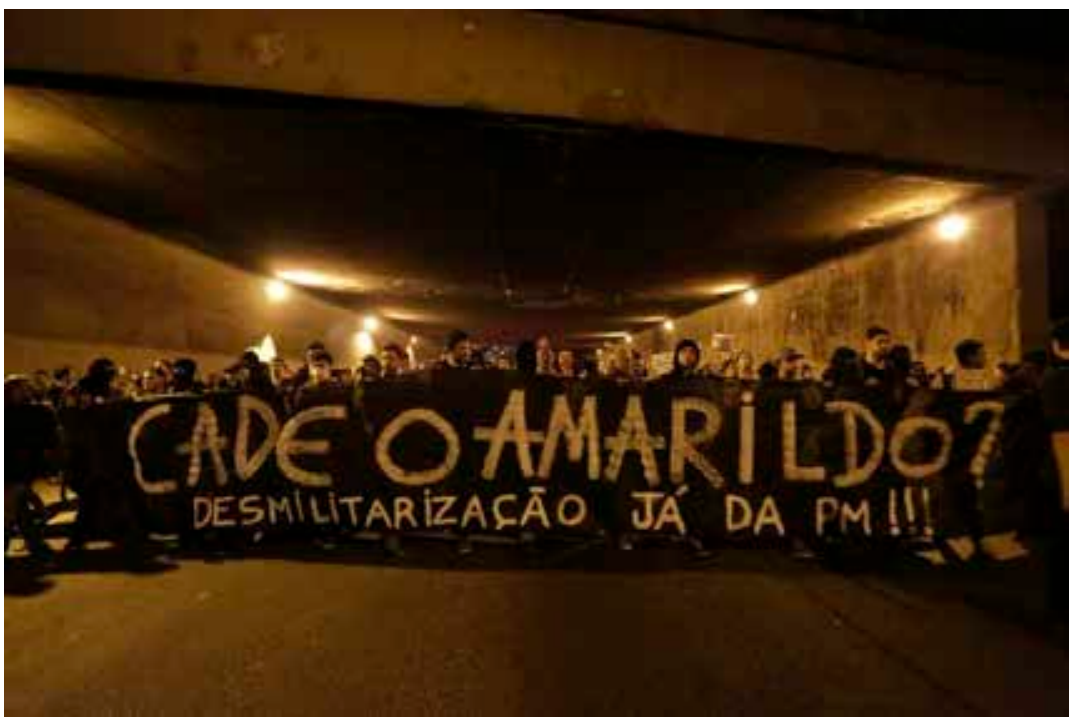

Fonte: <http://img.r7.com/images/2013/08/01/21_30_08_410_file?dimensions $=780 \times 536 \&$ no_crop=true $>$. Acesso em: 22 mar. 2014.

Os movimentos de 2013 acabaram coincidindo com o desaparecimento do ajudante de pedreiro Amarildo Dias de Souza, ocorrido em 14 de julho de 2013, após ter sido detido por policiais militares e conduzido da porta de sua casa, na Favela da Rocinha, à sede da Unidade de Polícia Pacificadora (UPP) do bairro. Seu desaparecimento 
tornou-se símbolo de casos de abuso de autoridade e violência policial, e a pergunta "Onde está Amarildo?" - a segunda palavra de ordem que quero comentar - tornou-se recorrente nas manifestações, estampada em faixas e cartazes e pichada nos muros de várias cidades. Mais uma vez o passado ajudou a questionar o presente e a tecer projetos de futuro, como a já mencionada desmilitarização da polícia. Até hoje não se sabe o que aconteceu com esse homem da favela, mas há fortes indícios de que ele tenha sido torturado e assassinado e que seu corpo tenha sido ocultado, como ocorreu com vários militantes que se opunham à ditadura. Sua família tem se mostrado incansável em encontrar respostas para aquelas perguntas que tanto assombram os familiares dos desaparecidos políticos: Como? Quando? De que maneira? Por quem? Onde está o corpo? Muitos poderão dizer que a comparação é anacrônica e meramente panfletária. Amarildo não tinha um projeto global de mudança da sociedade, nem lutava com armas na mão para realizá-lo; provavelmente seu projeto fosse apenas viver melhor. Mas a memória, conforme advogo apoiado em Todorov, deve ir além da sua literalidade, da sua historicidade específica, para guiar-nos à ação, à ampliação dos espaços democráticos.

Estes exemplos recentes - e aqui voltamos ao tema do quantitativo e do qualitativo com o qual comecei o artigo - mostram que mais do que "muita memória", precisamos de "boa memória", que esteja entre o excesso e a falta, pois ambas escapam à crítica e tendem ou à sacralização ou à manipulação. Como nos alerta Ricoeur, é preciso associar a memória com a noção de justiça, pois é ela que, extraindo das lembranças o seu valor exemplar, transforma a memória em projeto; "[...] e é esse mesmo projeto de justiça que confere ao dever de memória a forma do futuro e do imperativo" (RICOEUR, 2000, p. 107, tradução nossa). Só assim perguntas como “Onde está Rubens Paiva?” e "Onde está Amarildo?” poderão, para além das importantes demandas e dores privadas ligadas a esses desaparecimentos (que devem ser atendidas e respeitadas), nos ajudar a projetar e construir uma democracia vigorosa e uma cidadania plena. 


\section{HOW MUCH MEMORY DOES A DEMOCRACY NEED?} A REFLECTION ON THE RELATION BETWEEN MEMORIAL PRACTICES AND DEMOCRATIC PRACTICES IN TODAY'S BRAZIL

Abstract: The present article, structured in essay format, seeks to analyze the relationship between memorial practices and democratic practices, focusing on memorial projects in Brazil regarding the civil-military dictatorship, which took place in the country from 1964 to 1985 . To do so, this paper examines places of memory and other forms of expression by the civil society that evoke this authoritarian past, conceived as part of the transitional justice. It also affirms the need for an exemplary memory related to the dictatorship as a key element towards the process of building a strong democracy and enabling full citizenship. Keywords: Brazilian Dictatorship. Memory. Democracy. Transitional Justice.

\section{Notas}

${ }^{1}$ Refiro-me ao projeto Militância e solidariedade além-fronteiras - o grupo dos brasileiros do POC - Fracción Roja (1968-1979), apoiado com bolsa de produtividade do CNPq.

${ }^{2}$ Todas as informações sobre o Memorial da Resistência foram retiradas do seu site institucional: $\langle$ http://www.memorialdaresistenciasp.org.br/memorial/>. Acesso em: 22 mar. 2014.

${ }^{3}$ São eles: Casa do Massacre da Lapa, Convento dos Dominicanos e Livraria Duas Cidades, Fazenda 31 de Março de 1964, Rua Maria Antônia, Catedral e Praça da Sé, Teatro TUCA, Cemitério Dom Bosco - Vala de Perus e Sítio de Ibiúna. ${ }^{4}$ São eles: DOI-Codi, Instituto Cultural Israelita Brasileiro - ICIB, Centro Acadêmico XI de Agosto - Largo São Francisco, Presídio Tiradentes e Presídio Carandiru, e Sindicato dos Jornalistas.

${ }^{5}$ Todas as informações sobre o Museu Histórico Nacional foram retiradas do seu site institucional: 〈www.museuhistoriconacional.com.br〉. Acesso em: 22 mar. 2014.

${ }^{6}$ Disponível em: $<$ https://www.facebook.com/permalink.php?story_fbid=1515 05635024263\&id=151504575024369>. Acesso em: 22 mar. 2014.

Anos 90, Porto Alegre, v. 22, n. 42, p. 153-177, dez. 2015 


\section{Referências}

ACHUGAR, Hugo. El lugar de la memoria, a propósito de monumentos (motivos y parêntesis). In: JELIN, Elizabeth; LANGLAND, Victoria (Org.). Monumentos, memoriales y marcas territoriales. Madrid: Siglo XXI, 2003.

BATTAGLIA, Mattea. Entre histoire et morale, le malaise des élèves face à la Shoah. Le Monde, p. 10, 1 févr. 2014.

BRITO, Valdenia. El monumento para no olvidar: "Tortura Nunca Mais" en Recife. In: JELIN, Elizabeth; LANGLAND, Victoria (Org.). Monumentos, memoriales y marcas territoriales. Madrid: Siglo XXI, 2003.

CATELA, Ludmila da Silva. Territorios de memoria política: Los archivos de la represión em Brasil. In: CATELA, Ludmila da Silva; JELIN, Elizabeth (Org.). Los archivos de la represión: documentos, memoria y verdade. Madrid: Siglo XXI, 2002.

HARTOG, François. O tempo desorientado: Tempo e história. "Como escrever a história da França?” Anos 90, Porto Alegre, v. 5, n. 7, p. 7-28, jul. 1997.

KOSELLECK, Reinhart. Futuro Passado: contribuição à semântica dos tempos históricos. Rio de Janeiro: Contraponto; Ed. PUC-RJ, 2006.

MARTINS FILHO, João Roberto. Adieu à la dictature militaire? Brésil(s) Sciences Humaines et Sociales, Paris, n. 5, p. 17-32, 2014.

MELO, Demian Bezerra de. Ditadura "civil-militar"?: Controvérsias historiográficas sobre o processo político brasileiro no pós-1964 e os desafios do tempo presente. Espaço Plural, Cascavel, PR, Ano XIII, v. 13, n. 27, 2. sem. 2012.

MUSEU HISTÓRICO NACIONAL. Exposições de longa duração. Disponível em: 〈http://www.museuhistoriconacional.com.br/>. Acesso em: 22 mar. 2014.

TU SABE quem foi o ditador Costa e Silva? Nome de Ditador em Escola Não Eras, Porto Alegre, 28 abr. 2013. Disponível em: 〈https://www.facebook.com/ permalink.php?story_fbid $=151505635024263 \&$ id $=15150457502436>$. Acesso em: 22 mar. 2014.

O GLOBO. Apoio editorial ao golpe de 64 foi um erro. O Globo, Rio de Janeiro, 31 ago. 2013. Disponível em: <http://oglobo.globo.com/brasil/apoio-editorial -ao-golpe-de-64-foi-um-erro-9771604>. Acesso em: 22 mar. 2014.

PROST, Antoine. Comment l'Histoire fait-elle l'historien? Vingtième Siècle: Revue d'histoire, n. 65, p. 4-13, janv./mars 2000.

Anos 90, Porto Alegre, v. 22, n. 42, p. 153-177, dez. 2015 
RICOEUR, Paul. La mémoire, l'histoire, l'oubli. Paris: Seuil, 2000.

SÃO PAULO. Secretaria da Cultura. Memorial da Resistência de São Paulo Site institucional. Disponível em: $<$ http://www.memorialdaresistenciasp.org.br/ memorial/>. Acesso em: 22 mar. 2014.

TODOROV, Tzvetan. Los abusos de la memoria. Barcelona: Paidós, 2000.

ZYL, Paul van. Promovendo a justiça transicional em sociedades pós-conflito. In: REÁTEGUI, Félix (Org.). Justiça de Transição: Manual para a América Latina. Brasília, DF: Comissão de Anistia; Ministério da Justiça; Nova Iorque: Centro Internacional para a Justiça de Transição, 2011.

Recebido em: 09/03/2015 Aprovado em: 16/05/2015 